\title{
DEVELOPMENT OF VALUE ADDED TEA BAGS AND CAPSULES OF ARTEMISIA ANNUA ANAMED (A3) WHOLE PLANT FOR MALARIA TREATMENT
}

\author{
${ }^{1}$ Abolaji, G.T*., ${ }^{1}$ Olooto, F. M., and 2Williams, F. E. \\ ${ }^{1}$ Department of Agricultural Economics and Extension Service, College of Agriculture and Veterinary \\ Medicine, Kwara State University, Malete, Nigeria. \\ 2Department of Clinical Pharmacy and Pharmacy practice, University of Ilorin, Ilorin, Nigeria. \\ *Corresponding author Email: drgracea@hotmail.com or grace.abolaji@kwasu.edu.ng \\ Phone no: +2348160786999
}

\begin{abstract}
Malaria is one of the most serious diseases of global public health importance. Artemisinin-based Combination Therapy (ACT) has been adopted as the first-line treatment of uncomplicated malaria in Nigeria. However, ACTs are expensive; hence the need for production of Artemisia plants as a local alternative. Artemisia Annua Anamed (A-3) cultivar seeds were obtained from REAP in Kenya and propagated in Ilorin, Nigeria; based on the guidelines of Anamed International, REAP and WHO for growing, harvesting, and processing to value added products. Propagation to budding/harvesting took 4 months and fresh leaves were processed to dark green dried leaves which was developed to value added products of tea bags and powdered capsules following the Noble Icon NAFDAC approved procedures and equipment; and Now Food University in USA procedures and equipment respectively. Each tea bag of A-3 contained $2.5 \mathrm{~g}$ of pulverized dried leaves while each capsule contained $500 \mathrm{mg}$ of powdered dried leaves based on Anamed International dosage recommendations. Several studies supported the use of artemisia annua tea and capsules for the treatment of malaria pointing out that flavonoids existing in the leaves and stem considerably enhance the interest of its tea preparation and powdered leave capsules that are usable for rectal administration. It is recommended that there is the need to train the rural community people who are already using herbal medicine; and unable to reach or afford costly pharmaceutical ACT in the growing and development of the dried A-3 leaves as herb tea for malaria prevention and treatment. There is also the need for further studies to determine the active contents in the developed herb tea and the powdered capsules in order to be able to use them for treating malaria.
\end{abstract}

Key Words: Artemisia Annua Anamed, Herb Tea, Capsules, Malaria, Whole Plant

\section{INTRODUCTION}

Malaria: a protozoan infection caused by Plasmodium falciparum, Plasmodium vivax, Plasmodium malarae, Plasmodium ovale and Plasmodium klowlesi constitutes a global public health burden (Williams et al, 2013). It is one of the six killer diseases that were endemic in 106 countries of which 99 had on going malaria transmission. There are 33billion people at risk of malaria while 655 thousand malariarelated deaths of which $86 \%$ of children under five years old were reported in 2010 (Williams et. al., 2013). It is noteworthy that Nigeria and other 5 sub-Saharan African countries contributed $60 \%$ of the malaria related deaths (Williams et al, 2013). Rezelman and Goris (2008) also reported that about 1.5 million people die every year of malaria; and every 30 seconds a child dies due to this preventable and curable disease. Over $90 \%$ of malaria cases and the great majority of malaria deaths occur in sub-Saharan Africa. Most of the affordable antimalarial drugs have become ineffective because Plasmodium falciparum - the malarial parasite responsible for the most severe malaria cases and deaths - has developed resistance to them.

According to the World Health Organization (2006) and other agencies, artemisinin based combination therapies (ACTs), which contain derivatives of artemisinin (extracted from the plant Artemisia annua), are 
the most promising anti-malaria drugs for treating malaria. It has been estimated that there are roughly 500 million cases of clinical malaria per year, the majority of which should ideally be treated with an ACT. However, supply does not yet meet this biologically-induced need. The production and supply chain need to grow and significant public and private interventions are required to make an effective and affordable anti-malaria drug available to Nigerian populace. According to Abolaji (2013) in a pilot study, A-3 was grown and the leaves processed in to herb tea in Nigeria, the results of the pilot study showed that after using the tea extracted from the dried leaves of the A-3; four individuals felt calm and relaxed, had sound night sleep, cleared nasal and head stuffiness', and felt relieved from malaria symptoms on the third day of taking a liter of tea per day for 7 days.

According to Alexander (2012) the Malaria Indicator Survey conducted by the National Malaria Control Program (NMCP) in 2010 showed that malaria was the major cause of anemia in 72 percent of Nigerian children. Malaria was still endemic in the country due to non-adherence on the part of Nigerians to malaria preventive measures. Several studies have proved that Artemisia annua plant could be cultivated by seed and stem propagation and be used in different forms such as tea, capsules, ornamentals around houses, and burning coils to kill malaria parasites. The cultivar A-3 is adaptable to the tropical climate; and could be grown, processed and used without any side effects. There is therefore the need to carry out an experimental cultivation of A-3 by seed propagation and processing into different easily usable value added products such as dried leaves herb tea and dried leaves powder capsules in Kwara state Nigeria. These products could become potential tools to fight malaria in remote rural areas and populations that could not easily access or afford the pharmaceutical ACT. The aim and objective of this study is therefore to grow and process the leaves of A3 to herbal tea and capsules for the treatment of malaria.

\section{MATERIALS AND METHODS}

Artemisia Annua Anamed (A-3) cultivar seeds were obtained from REAP in Kenya. At the beginning of the raining season in April, loam soil was collected from the medicinal garden in South East llorin, Kwara state Nigeria. The soil was sift into a big plastic bowl using plastic strainer and sterilized by covering the big plastic bowl with black plastic sheet for 5 days in the direct sunlight. This method of sterilization was to kill most of the weed seeds, pests and disease causing microorganisms in the sifted soil. Recycled paint bucket horizontally cut into half with holes at the bottom was filled with the sifted soil and placed in a bigger plastic bowl filled with water to about $1 / 3$ of the height of the paint bucket. This is to provide capillary irrigation system to the propagated seeds. Because A-3 seed size is very small and can be easily blown away during sowing, the seeds were mixed with sparingly moist fine sandy soil and spread evenly on the soil in the plastic paint bucket and placed in the sunlight.

A-3 germinated on the 4th day and on the 10th day; the seedlings were separated individually into seedling plastic bags filled with the sifted loam soil. After 4 weeks, the individual seedlings were transplanted at $80 \mathrm{~cm}$ distance apart on the prepared row ridges; and watered twice daily until 3 months later when the plants showed the sign of flower budding. The A-3 plants were harvested by cutting the stem close to the root base and transported to Noble Icon Living Healthy within the hour of harvesting.

The harvest was washed with spray head nozzle to get rid of sand and foreign objects, and arranged in the solar drying trays in the Noble Icon commercial solar dryer to dry within 4 hours of the sunny day. The dried leaves were shaken off from the plants and transferred to the different grinders that processed them to leave powder and tea bags respectively. The powdered A-3 capsules were produced using the empty gelatin capsules and manual capsule making machine (purchased from NOW Foods Company in United States of America). 


\section{RESULTS AND DISCUSSION \\ Growing A-3 from Seed Propagation}

A-3 was successfully established and grown by seed propagation following a combination of guidelines stated by WHO (2006), Anamed International (2011) and REAP (2013). As shown in Table 1, propagated seeds of A-3 germinated after 4 days, seedlings were ready for separation into individual plastic seedling pots after 10 days, and transplanted into the field after 6 weeks. The plants grew for additional 8 weeks ( 2 months) when it started showing flower buds at the point which they were harvested, dried and processed to value added products of herb tea and powdered capsules. Thus following a combination of cultivation guidelines by World Health Organization, Anamed International and Rural Extension in Agriculture for the Poor Organization, it was possible to propagate A-3 by seeds and grown the plants to the point of harvest within 4 months in Ilorin, Kwara State, Nigeria.

Table 1: Time Table for Seed Propagation and Growing of Artemisia annua Anamed (A-3)

Activities

A-3 seed sowing

Germination

Seedlings separation into seedling pots

Seedlings transplanting to the field

Harvesting of A-3 whole plants

Dates Time Duration

$\begin{array}{ll}\text { April 17, } 2014 & \\ \text { April 21, 2014 } & 4 \text { days } \\ \text { May 1, 2014 } & 10 \text { days } \\ \text { June 12, } 2014 & 42 \text { days (6 weeks) } \\ \text { August } 9,2014 & 58 \text { days (8 weeks) }\end{array}$

August 9, 201458 days (8 weeks)
Sowing-Germination-Separation-

Transplanting-harvesting
April 17-August 9, 2014114 days=16 weeks-4 months

\section{Harvesting and Processing of Artemisia annua to Dried Leaves}

The whole fresh plants of A-3 grown in this study were obtained by cutting to the root base after 4 months of seed propagation and at the point of flower budding. This was supported by WHO (2006); Anamed International (2012); and REAP (2013) harvesting guidelines which indicated that the best harvesting time is the early stage of flower budding since the yield of $A$. annua leaves and the content of artemisinin are reduced if harvesting is too early or is delayed.

As shown in Figs.1 and 2, harvested plants were dried in the Noble Icon's commercial solar dryer and dark green color of dried leaves of A-3 was obtained respectively. This result is supported by Anamed International (2011) and REAP (2013) that pointed out that dried leaves of medicinal plants should have dark green color.

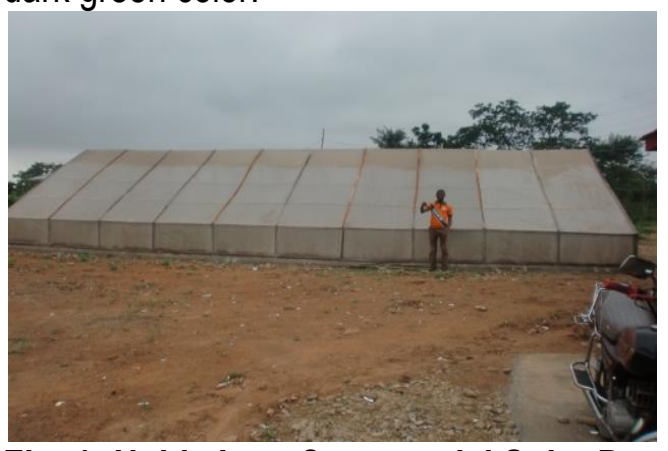

Fig. 1: Noble Icon Commercial Solar Dryer

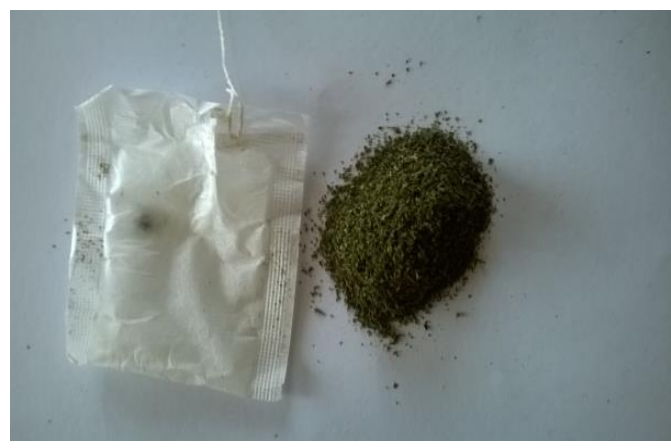

Fig. 2: Dark Green Pulverized Dried A-3

These are supported by WHO (2006) that indicated that comparisons between sun-drying, shade-drying and oven-drying at $60^{\circ} \mathrm{C}$ have shown that natural sun-drying is the best method; and when 
the leaves of $A$. annua have dried, the branches are stroked or shaken to detach the leaves from the stalks.

\section{Production of Value Added Products of Artemisia annua Anamed (A-3)}

As shown in Figures 3 and 4, Herb Tea Bags and Powdered Capsules of A-3 were produced in this study following a combination of processing and packaging guidelines of Anamed International (2012), REAP (2013) and Noble Icon (2014) NAFDAC certified equipment and procedures. Each tea bag of A-3 contained $2.5 \mathrm{~g}$ of pulverized dried plant while each capsule contained $500 \mathrm{mg}$ of powdered dry leaves.

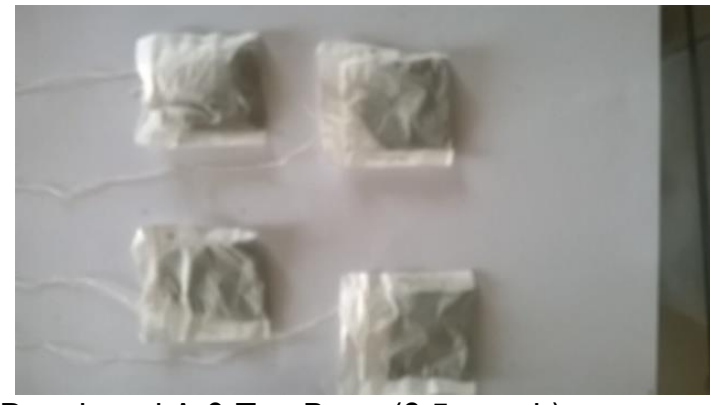

Fig3: Developed A-3 Tea Bags (2.5g each)

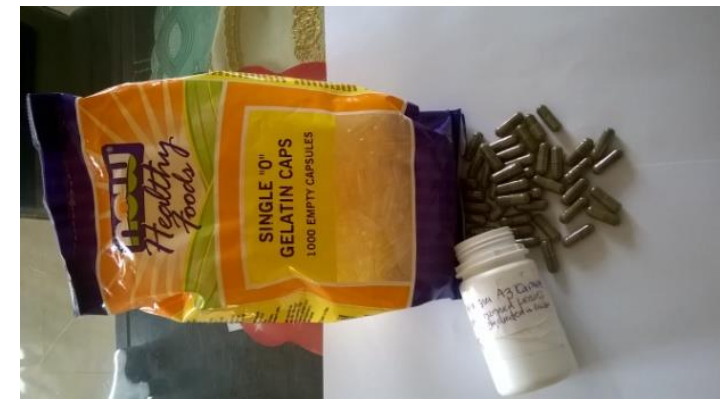

Fig4: Developed A-3 Capsules (500g each)

This is in line with Anamed International (2012) and REAP (2013)'s dosage recommendations. Thus, the growing, development and use of the dried A-3 leaves as herb tea for malaria prevention and treatment could be taught to the rural community people that are already using herbal medicine; and unable to reach or afford costly pharmaceutical ACT.

In support of the results of this study, Onimus et. al., (2013) indicated that tea preparation from Artemisia annua was used in traditional Chinese medicine for centuries and it has been proved to be effective and safe in treatment of all human malarial parasites, and notably multidrug-resistant plasmodium falciparum. According to Chiung-Sheue et. al., (1992), the pharmacopoeia of the People's Republic of China officially listed the dried herb of $A$. annua as a remedy for fever and malaria. The daily dose was specified as 4.5 to 9 grams of dried herb to be prepared as a tea infusion with boiling water. Elfawa et. al. (2012); Ferreira (2010); Goulart, et al.(2004); and Swarthout, et. al., (2006) indicated that flavonoids existing in the leaves and stem of Artemisia annua considerably enhance the interest of the Artemisia annua tea preparation as a treatment of malaria. They also indicated that an alternative to the tea preparation is the use of powdered leaves, or given in capsules which are easier to use than the tea (Williams et al, 2013).

\section{CONCLUSIONS AND RECOMMENDATION}

Based on the results of this study, the following conclusions were made: Artemisia annua Anamed (A-3) was propagated by seeds and the plants were grown to the point of harvest within 4 months in llorin, Kwara State Nigeria following a combination of cultivation guidelines by World Health Organization, Anamed International and Rural Extension in Agriculture for the Poor (REAP) Organization. Dark green colored dried leaves of A-3 were obtained in this study and this was in line with the good quality standard described and obtained by Anamed International and REAP. Also, Artemisia Annua Anamed (A-3) tea bags each containing $2.5 \mathrm{~g}$ of pulverized dried leaves and capsules each containing $500 \mathrm{mg}$ of powdered dried leaves were developed.

The following recommendations were made based on the conclusions made from this study: There is the need to train rural community people who are already using herbal medicine; and unable to reach or afford costly ACT drug on the growing and development of the dried A-3 leaves as herb tea for malaria prevention and treatment. There is also the need for further studies to determine the dose of 
artemisinin contents needed in the form of the developed herb tea and the powdered capsules in order to be able to use them for treating malaria.

\section{REFERENCES}

Abolaji, G. T.(2013). Artemisia annua Growing and Processing as Malaria Treatment for the Rural Poor in Nigeria. Proceedings of the First U6 Consortium International Conference. 2013; 250-281.

Anamed (Action for Natural Medicine), (2011). Welthungerhilfe Rwanda, Artemisia Training Manual. Schafweide 77; 71364 Winnenden, Germany; www.anamed.net. Dr. Hans-Martin Hirt: anamedhmh@yahoo.de; Dr. Keith Lindsey: anamed@t-online.de

Alexander C. (2012). AHTTP//BUSINESSONLINE.COM YOU ARE HERE: HOME Nigeria unlikely to reduce malaria case by 75\% in 2015 FRIDAY, 28 DECEMBER 2012 00:00.

Chiung-Sheue Chen Liu K., Yang S.L., Roberts M.F., Elford B.C., Phillipson J.D. (1992) Antimalarial activity of Artemisia annuaflavonoids from whole plants and cell cultures. Plant Cell Reports,11; 637-40.

Ferreira J.F.S., Luthria D. Sasaki T., and Heyerick A. (2010): Flavonoids from Artemisia annuaas antioxidants and their potential synergism with artemisinin against malaria and cancer. Molecules, 15, 3135-3170

Golenbock D, Weathers PJ(2012). Dried Whole Plant Artemisia annua as an Antimalarial Therapy. PLoS ONE. 2012; 7(12): e52746.

Goulart H. R., Kimura E. A., Peres V. J., Couto A. S., Aquino Duarte F.A. and Katzin A. M. (2004): Terpenes Arrest Parasite Development and Inhibit Biosynthesis of Isoprenoids in Plasmodium falciparum Antimicrobial Agents and Chemotherapy, July, 48 : 2502-9.

Noble Icon Nigeria Company (2014). Living Healthy.www.nobleiconng.com.

Onimus M, Vouillot J.M., Clerc G. (2013): Artemisia Annua, A whole against malaria: A program of local production for treatment of malaria in poorest countries. ArtémisiaContrePaludismewww.acp paludisme.org Amis Comtois des Missions Centrafricaines www.acmc-ong.net

Pageant (2013). Education is the future". The Artemisia Project. Helping to combat malaria in Gambian villages.

REAP (2013). Agricultural Medicinal Plant Training Seminar Leaflet

Rezelman D. and Goris H. (2008): The role of herbal products containing Artemisia annua in malaria treatment. A proposal for further research. Concept 01 October.

Swarthout T.D., van den Broek I.V., Kayembe G., Montgomery J., Pota H. and Roper C. (2006): Artesunate + amodiaquine and artesunate + sulphadoxine-pyrimethamine for treatment of uncomplicated malaria in Democratic Republic of Congo: a clinical trial with determination of sulphadoxine and pyrimethamine-resistant haplotypes. Trop Med Int Health., 11: 1503-11.

Williams F. E., Animashaun J.O., Ibrahim A. and Toye A.A. (2013): Preliminary Survey on Consumption of Moringa Products for Nutraceutical Benefits in Ilorin, Kwara State, Nigeria. Agrosearch 13 (1): 165-175

Williams F. E., Jolayemi E.T., and Adje D.U. (2013): Antimalarial Medicines Use Among Mothers Attending a Secondary Public Hospital in North Central Nigeria for their Under-five Children. Implications for Sustainable Health Transformation for African Development. Proceedings of the First U6 Consortium International Conference. 320-340

World Health Organization (2006). WHO monograph on good agricultural and collection practice (GACP) for Artemisia annua L. 